\title{
Effect of Soybean on Bone Health and Some Metabolic Parameters in Postmenopausal Egyptian Women
}

\author{
Mouchira Abdel Salam', Hala M. Raslan², Doha A. Mohamed ${ }^{3}$, Aliaa Elgendy', Rehab A. Hussein ${ }^{4, *}$, Omneya \\ Moguib $^{2}$, Maha Abdelhadi ${ }^{2}$, Rokia Abd El-Shafy Soliman El-Banna ${ }^{5}$, Karem Fouda ${ }^{3}$, Safenaz Y. El Sherity ${ }^{5}$, \\ Emad N. Zikri', Nagwa M. Ammar ${ }^{3}$
}

\begin{abstract}
Mouchira Abdel Salam ${ }^{1}$, Hala M. Raslan², Doha A. Mohamed ${ }^{3}$, Aliaa Elgendy', Rehab A. Hussein $^{4, *}$, Omneya Moguib ${ }^{2}$, Maha Abdelhadi², Rokia Abd ElShafy Soliman El-Banna ${ }^{5}$, Karem Fouda $^{3}$, Safenaz Y. El Sherity ${ }^{5}$, Emad N. Zikri' ${ }^{1}$ Nagwa M. Ammar ${ }^{3}$

'Complementary Medicine Department, National Research Centre, Dokki, Cairo, EGYPT.

IInternal Medicine Department, National Research Centre, Dokki, Cairo, EGYPT.

${ }^{3}$ Nutrition and Food Sciences Department, National Research Centre, Dokki, Cairo, EGYPT.

${ }^{4}$ Pharmacognosy Department, National Research Centre, Dokki, Cairo, EGYPT. ${ }^{5}$ Biological Anthropology Department, National Research Centre, Dokki, Cairo, EGYPT.
\end{abstract}

\section{Correspondence}

\section{Rehab A. Hussein}

Pharmacognosy Department, National Research Centre, Dokki, Cairo, EGYPT.

Phone no: +201000955449;

Fax +20233371362 ;

E-mail: rehaba.husein@yahoo.com History

- Submission Date: 11-01-2021;

- Review completed: 26-02-2021;

- Accepted Date: 02-03-2021.

DOI : 10.5530/pj.2021.13.88

Article Available online

http://www.phcogj.com/v13/i3

Copyright

(C) 2021 Phcogi.Com. This is an openaccess article distributed under the terms of the Creative Commons Attribution 4.0 International license.

\section{ABSTRACT}

Introduction: Great concern has been raised recently concerning the therapeutic impact of soybean. The present study aims to investigate the effects of soybean on bone health and metabolic parameters in postmenopausal women. Methods: In this clinical study, 72 healthy postmenopausal women aged between 45-65 years were given soybean bioactive fraction 2 capsules (500mg each) daily for 24 weeks. Each capsule contained $31.25 \mathrm{mg}$ proteins, 3.2 $\mathrm{mg}$ carbohydrates and $4.84 \mathrm{mg}$ isoflavones. Blood pressure, bone mineral density, plasma osteocalcin (OCN), telopeptides of collagen type I (CTX), fasting insulin and blood glucose, lipid profile, serum creatinine, alanine transaminase (ALT), aspartate transaminase (AST), and TSH were assessed prior and after the period of the study. Insulin resistance was calculated by homeostatic model assessment-IR formula (HOMA-IR). Results: Soy ingestion resulted in a significant increase in T score of the hip and OCN; recording $-1.97 \pm 0.13 /-1.76 \pm 0.12$ and $22.44 \pm 0.60 \mathrm{ng} / \mathrm{ml} / 30.93 \pm 0.57 \mathrm{ng} / \mathrm{ml}$ before/after treatment, respectively. A marked decrease was also detected in CTX from $2.22 \pm 0.10 \mathrm{ng} / \mathrm{ml}$ to $1.48 \pm 0.08 \mathrm{ng} / \mathrm{ml}$. With regard to metabolic parameters, there was a significant decrease in fasting insulin $(5.40 \pm 0.62 \mathrm{uU} / \mathrm{ml}$ vs $4.15 \pm 0.45 \mathrm{uU} /$ $\mathrm{ml}$ ), however, fasting glucose and HOMA-IR showed no significant alterations. Lipid profile displayed remarkable decline in total cholesterol $(188.86 \pm 7.23 \mathrm{mg} / \mathrm{dl}$ vs $159.60 \pm 4.72 \mathrm{mg} / \mathrm{dl}$, triglycerides $(97.09 \pm 5.23 \mathrm{mg} / \mathrm{dl}$ vs $83.56 \pm 4.27 \mathrm{mg} / \mathrm{dl})$, LDL-c $(75.60 \pm 3.06 \mathrm{mg} / \mathrm{dl}$ vs $63.95 \pm 1.86 \mathrm{mg} /$ dl) accompanied with a significant elevation in HDL-c $(53.09 \pm 0.88 \mathrm{vs} 65.81 \mathrm{mg} / \mathrm{dl} \pm 0.80 \mathrm{mg} /$ dl). A significant decrease in both TSH $(1.97 \pm 0.13 \mathrm{ulU} / \mathrm{ml}$ vs $1.40 \pm 0.08 \mathrm{ulU} / \mathrm{ml})$ and serum creatinine $(0.82 \pm 0.02 \mathrm{mg} / \mathrm{dl}$ vs $0.77 \pm 0.02 \mathrm{mg} / \mathrm{dl})$ was also noticed. Conclusion: Consumption of soy improves bone health, reduces cardiovascular risk with no adverse effects on kidney, liver or thyroid functions.

Key words: Bone health, Bone mineral density, Hypocholesterolemic effect, Insulin resistance, Metabolic parameters, Soybean.

\section{INTRODUCTION}

Menopause is a natural biological process resulting from loss of ovarian follicle development and decreasing level of circulating estrogen. It is associated with increased risk of cardiovascular diseases and osteoporotic fractures ${ }^{1}$. The manifestations of low estrogen level though commonly treated by hormone replacement therapy (HRT), the latter is evidently related with increased risk of breast cancer, thromboembolic conditions, gall bladder and liver disease ${ }^{2}$, which provokes the search for complementary medicine with minimal side effects. Over the recent decades, researchers have been interested in the health benefits of soy and soy-products. It has been postulated that soy consumption may improve cardiovascular and bone health ${ }^{3}$.

Soybeans (Glycine max L. Merrill) were first grown as a crop in China about 5000 years ago and have been widely consumed as folk medicines in China, India, Japan and Korea for hundreds of years. It is a rich source for protein and isoflavones. Isoflavones are classified as phytoestrogens with structural similarity to $17 \beta$-estradiol. Isoflavones exhibit weak estrogenic activity as they interact with estrogen receptor (ER) ER- $\beta$ and to a lesser extent ER- $\alpha$, so they were considered as selective ER modulators, and potential alternatives to $\mathrm{HRT}^{4}$. There are 12 different isoflavones detected in soybean: three aglycones; genistein, daidzein and glycitein, their respective $\beta$-glycosides; genistin, daidzin and glycitin along with the $3 \beta$-glucosides each esterified with either malonic or acetic acid ${ }^{5}$.

The aim of the current study was to investigate the beneficial effects of the oral administration of the bioactive fraction of soybean prepared in the form of hard gelatinous capsules containing a dose of (500mg) to be taken one capsule 2 times daily for 24 weeks on bone mineral density, bone turnover markers and some metabolic parameters in postmenopausal women.

Cite this article: Salam MA, Raslan HM, Mohamed DA, Elgendy A, Hussein RA, et al. Effect of Soybean on Bone Health and Some Metabolic Parameters in Postmenopausal Egyptian Women. Pharmacog J. 2021;13(3): 688-97. 


\section{MATERIALS AND METHODS}

Phytochemical study

\section{Plant material}

Seeds of Glycine max L. were purchased from Harraz herbal store, Cairo, Egypt and identified by the vice-head of the partial experimental unit of the faculty of Agriculture Cairo University, Mr. Eid Yossef Mohammed.

\section{Preparation of the polar fraction of Soy}

The finely grinded powder of the seeds of G. $\max$ L. was macerated in a $70 \%$ aqueous-ethanol (Fisher Scientific, Loughborough, Leics, UK) solvent system at $50^{\circ} \mathrm{C}$ several times till exhaustion. The solvents were removed from the collected fractions by evaporation in a rotatory evaporator under reduced pressure at a temperature not exceeding 60 ${ }^{\circ} \mathrm{C}$. The final product was introduced into a lyophilizer for the removal of moisture content. A friable powder was obtained which was used for the phytochemical analysis. The lyophilized biologically active and safe fraction of Soybean, rich in isoflavones, which revealed previously a potent and safe estrogen-like activity in ovariectomized rats [Project No. 1190401, NRC, Egypt, 2017paper in press] was encapsulated in hard gelatinous capsules according to the British Pharmacopoeia, 1993 and the National Formulary, 1975.

Estimation of total proteins, total carbohydrates and total isoflavones were done according to Horwitz, $2005{ }^{6}$ Masuko et al., $2005^{7}$ and César et al., $2008^{8}$.

LC-DAD/ESI-MS analysis of the bioactive fraction of Glycine max L. was done according to Kamo et al., 2014. ${ }^{9}$

\section{Clinical study}

\section{Patients}

In the present study, seventy-two postmenopausal women aged between 45 and 65 years were recruited from internal medicine and complementary outpatient clinics of Medical Services Unit at National Research Centre (NRC). A detailed questionnaire was taken from every participant including age at menopause, history of tobacco intake, dietary habits, drug history, medical history and family history of breast cancer. Clinical examination was done including height and weight measurements and calculation of body mass index (BMI) and breast examination. Inclusion criteria were women with normal menopause, age: 45-65 years and with abnormal bone mass density (BMD) by DEXA (osteopenia or osteoporosis) at the lumbar spine and/ or proximal femur.

Exclusion criteria: Women with normal bone mineral density (BMD) by DEXA, women receiving hormone replacement therapy or medications that could affect bone metabolism such as steroid bisphosphonates or thyroxine, diabetes mellitus, hypertension, dyslipidemia, women with major medical illnesses like myocardial infarction, stroke, congestive heart failure, liver or kidney disease, history of malignant disease or family history of cancer breast were excluded.

\section{Laboratory tests}

Blood samples were collected from all women after fasting for 12-14 hours and the samples were divided into two parts. The first part was collected in tubes containing EDTA for complete blood count (CBC) and the second part was collected in tubes containing heparin. The tubes containing the second part of blood samples were centrifuged at $3500 \mathrm{rpm}$ for separation of plasma. Plasma samples were collected for determination of total cholesterol (TC), high density lipoprotein cholesterol (HDL-c), low density lipoprotein cholesterol (LDL-c) and triglycerides (TG) according to Watson, 1960, Burstein et al., 1980,
Schriewer et al., 1984 and Megraw et al., 1979, respectively 10111213. Alanine transaminase (ALT) and aspartate transaminase (AST) and serum creatinine were estimated according to Reitman and Frankel, $1957^{14}$ and Houot, $1985^{15}$, respectively. Plasma insulin and blood glucose were determined according to Turkington et al., $1982{ }^{16}$ and Trinder, $1969^{17}$, respectively. Insulin resistance was calculated based on homeostasis model assessment of insulin resistance (HOMA-IR), according to Matthews et al., $1985^{18}$. The equation is

HOMA-IR $=[$ FPG $(\mathrm{mmol} / \mathrm{l}) \times$ FPI $(\mu \mathrm{U} / \mathrm{mL})] / 22.5$

In addition, plasma osteocalcin (OCN) as marker of bone turnover ${ }^{19}$ and plasma telopeptides of collagen type I (CTX) ${ }^{20}$ as bone resorption marker were determined using ELISA technique as well as plasma TSH ${ }^{21}$.

\section{Assessment of BMD}

Bone mineral density was measured at lumbar spine and left upper femur by Dual Energy X-Ray Absorptiometry (DEXA) using Norland XR46.

\section{Study design}

Prior to the study, the protocol was approved by the ethical committee of the National Research Centre (n:16/360). Written informed consent was taken from each participant. Women with osteopenia or osteoporosis at lumbar spine and/or upper femur were given soy capsule in a dose of 1 capsule $(500 \mathrm{mg}$ ) twice daily after meals for 24 weeks. Follow up was done every 2 weeks to check for compliance and any adverse events. Measurement of blood pressure, assessment of height and weight and calculation of BMI and all laboratory tests were repeated at the end of the study. T score was used for evaluating bone density. A T score of -1 and above is considered normal. A T score between -1.1 and more than -2.5 is classified as osteopenia. A T score of -2.5 and below is classified as osteoporosis ${ }^{22}$.

\section{Statistical analysis}

The results were expressed as Mean \pm SE. The results were analyzed statistically using Student's t-test (2-tailed) and a significance level of $p$ $<0.05$ was used as the criterion of statistical significance.

\section{RESULTS}

A number of seventy-two women were subjected to clinical examination, laboratory investigations and BMD assessment by DEXA. Seventeen women were excluded as they had normal BMD at hip and lumbar spine. Fifty-five women fulfilled the inclusion criteria and took the treatment. Twelve women dropped out during the study, two of them reported epigastric pain and the other ten did not return for follow up although they were called several times and did not report any adverse effects. Forty-three women completed the trial for 24 weeks. Their ages ranged from 45 to 65 years, mean: $53.93 \pm 5.24$ years. None of them was a smoker. Nineteen of them $(44.2 \%)$ reported history of caffeine intake and $7(16.3 \%)$ of gaseous beverages.

\section{Phytochemical analysis of soy bioactive fraction}

The phytochemical analysis of Soy (G. max L.) bioactive fraction revealed the presence of $31.25 \mathrm{mg}$ total proteins, $3.2 \mathrm{mg}$ total carbohydrates and $4.84 \mathrm{mg}$ total isoflavones. LC-DAAD/ESI-MS analysis resulted in the separation and identification of 12 compounds 8 of which belong to the class of isoflavones to which the estrogenic activity is attributed. Additionally, 4 soyasaponins were identified although they were present in minute percentages (Figure 1) (Table 1).

The proportions of genistein, daidzein and glycitein are 15.19, 9.56 and $4.19 \%$ respectively present either free or as their glucoside conjugates. 
<smiles>O=c1c(-c2ccc(O)cc2)coc2cc(OC3OC(CO)C(O)C(O)C3O)cc(O)c12</smiles><smiles>O=c1c(-c2ccc(O)cc2)coc2cc(OC3OC(CO)C(O)C(O)C3O)ccc12</smiles><smiles>COc1cc2c(=O)c(-c3ccc(O)cc3)coc2cc1OC1OC(CO)C(O)C(O)C1O</smiles>

Glycitein-7-glucoside<smiles>CCC12CCC3C(C)(CO)C(OC4OC(C(=O)O)C(O)C(O)C4OC4OC(CO)C(O)C(O)C4OC4OC(C)C(O)C(O)C4O)CCC3(C)C1CC=C1C3CC(C)(C)CC(=O)C3(C)CCC12C</smiles>

Soyasaponin E II<smiles>CCCCCCCCCCCC12CCC3C(C)(CO)C(OC4OC(C(=O)O)C(O)C(O)C4OC4OC(CO)C(O)C(O)C4OC4OC(CO)C(O)C(O)C4O)CCC3(C)C1CC=C1C2CC(C)(C)CC(O)C1(C)CC</smiles>

Soyasaponin V

Figure 1: Chemical structures of major phytoconstituents identified in Soy bioactive polar fraction.

Effect of soy on bone mineral density (BMD) and bone turnover markers

There was a significant improvement in BMD at the left upper femur after soy intake for 24 weeks with no significant effect at lumbar spine. Osteocalcin; a bone forming marker, showed significant increase and CTX; a marker of bone degradation, decreased significantly after soy intake (Table 2).

\section{Effect of soy on metabolic parameters}

A significant decrease in ALT, AST, serum creatinine, fasting insulin and TSH was indicated after soy intake. The lipid profile also showed improvement as TC, TG and LDL-c decreased and HDL-c increased after soy intake. No significant change in blood pressure, BMI, fasting glucose was recorded (Table 3 ). 
Table 1: Compounds identified by LC-DAD/ESI-MS in the bioactive fraction of Glycine max L, their retention times (RT), major ion peaks and percentages of area under the curve.

\begin{tabular}{|c|c|c|c|c|}
\hline & Compound & Rt & $\mathrm{m} / \mathrm{z}$ & AUC $\%$ \\
\hline 1 & Soysaponin Bb’ (III) & 2.21 & 795,633 & trace \\
\hline 2 & Soysaponin E-II & 6.77 & 909,884 & $0.06 \%$ \\
\hline 3 & Soysaponin Bc' (IV) & 7.89 & 765,457 & $0.02 \%$ \\
\hline 4 & daidzein 7-glucoside & 10.23 & 415,253 & $6.46 \%$ \\
\hline 5 & glycitein 7-glucoside & 10.86 & 445,283 & $4.02 \%$ \\
\hline 6 & Soysaponin $\mathrm{Ba}(\mathrm{V})$ & 10.89 & $939\left[\mathrm{M}-\mathrm{H}-\mathrm{H}_{2} \mathrm{O}\right]$ & $0.03 \%$ \\
\hline 7 & genistein-7-glucoside & 12.318 & 431,269 & $12.73 \%$ \\
\hline 8 & daidzein-7-malonylglycoside & 13.63 & 457,253 & $1.95 \%$ \\
\hline 9 & genistein 7-malonylglucoside & 15.256 & 473,269 & $1.23 \%$ \\
\hline 10 & Daidzein & 13.643 & 253 & $1.15 \%$ \\
\hline 11 & Glycitein & 14.15 & 283 & $0.17 \%$ \\
\hline 12 & Genistein & 15.305 & 269 & $1.23 \%$ \\
\hline
\end{tabular}

Table 2: Bone mineral density (BMD) and bone turnover biomarkers before and after soy intake.

\begin{tabular}{|ccc|}
\hline Parameters & Before soy & After soy \\
\hline T score of hip & $-1.97 \pm 0.13$ & $-1.76^{*} \pm 0.12$ \\
\hline T score of lumbar spine & $-1.47 \pm 0.13$ & $-1.47 \pm 0.14$ \\
Osteocalcin $(\mathrm{ng} / \mathrm{ml})$ & $22.44 \pm 0.60$ & $30.93^{*} \pm 0.57$ \\
CTX $(\mathrm{ng} / \mathrm{ml})$ & $2.22 \pm 0.10$ & $1.48^{*} \pm 0.08$ \\
\hline
\end{tabular}

Values significantly differ according to T-test: ${ }^{\star}$ : significant $<0.05$, CTX: telopeptides of collagen type I

Table 3: Clinical and biochemical parameters before and after soy (Mean \pm SE).

\begin{tabular}{ccc}
\hline Parameters & Before soy & After soy \\
\hline BMI $\left(\mathrm{kg} / \mathrm{m}^{2}\right)$ & $31.70 \pm 0.79$ & $31.39 \pm 0.83$ \\
SBP $(\mathrm{mmHg})$ & $123.26 \pm 2.37$ & $123.26 \pm 2.16$ \\
DBP $(\mathrm{mmHg})$ & $76.63 \pm 1.62$ & $77.33 \pm 1.50$ \\
ALT(U/l) & $11.35 \pm 0.71$ & $9.02^{*} \pm 0.35$ \\
AST(U/l) & $8.49 \pm 0.65$ & $6.44^{*} \pm 0.41$ \\
Creatinine(mg/dl) & $0.82 \pm 0.02$ & $0.77^{\star} \pm 0.02$ \\
F Glucose $(\mathrm{mg} / \mathrm{dl})$ & $98.85 \pm 6.02$ & $94.73 \pm 5.54$ \\
F Insulin(uU/ml) & $5.40 \pm 0.62$ & $4.15^{*} \pm 0.45$ \\
HOMA & $1.54 \pm 0.30$ & $1.30 \pm 0.26$ \\
Total cholesterol(mg/dl) & $188.86 \pm 7.23$ & $159.60^{*} \pm 4.72$ \\
Triglycerides $(\mathrm{mg} / \mathrm{dl})$ & $97.09 \pm 5.23$ & $83.56^{*} \pm 4.27$ \\
HDL-c $(\mathrm{mg} / \mathrm{dl})$ & $53.09 \pm 0.88$ & $65.81^{*} \pm 0.80$ \\
LDL-c $(\mathrm{mg} / \mathrm{dl})$ & $75.60 \pm 3.06$ & $63.95^{*} \pm 1.86$ \\
TSH $(\mathrm{uIU} / \mathrm{ml})$ & $1.97 \pm 0.13$ & $1.40^{*} \pm 0.08$ \\
Hb $(\mathrm{gm} / \mathrm{dl})$ & $13.01 \pm 0.15$ & $12.83 \pm 0.16$ \\
TLC $\left(10^{3} / \mathrm{cmm}\right)$ & $5.98 \pm 0.29$ & $6.11 \pm 0.28$ \\
PLT $\left(10^{3} / \mathrm{cmm}\right)$ & $264.49 \pm 7.91$ & $263.37 \pm 8.64$
\end{tabular}

Values significantly differ according to T-test: ${ }^{*}$ : significant $<0.05$, BMI: body mass index, SBP: systolic blood pressure, DBP: diastolic blood pressure, ALT: alanine transaminase, AST: aspartate transaminase, F: fasting, HDL: high density lipoprotein, LDL: low density lipoprotein, TSH: thyroid stimulating hormone, Hb: hemoglobin, TLC: total leucocytic count, PLT: platelets

\section{DISCUSSION}

Soy foods have long been a subject of scientific investigation due to the medical advantages related with their utilization as they have protective impact against osteoporosis and cardiovascular diseases ${ }^{23}$. In the present study, the effect of soy on bone health and some metabolic parameters was investigated in apparently healthy Egyptian postmenopausal women. Studies assessing the effects of soy isoflavones on bone health showed a lot of discrepancy. In the current study, we observed a significant increase in mean osteocalcin levels along with a significant decrease in mean CTX levels after soy isoflavones ingestion. Additionally, there was an increase in BMD at proximal femur after ingestion of soy capsules with no change in BMD at lumbar spine.
Lee and his colleagues reported increase in bone formation markers: Bone alkaline phophatase and osteocalcin in postmenopausal women after ingestion of $70 \mathrm{mg}$ isoflavones daily for 12 weeks ${ }^{24}$. A significant increase in BMD at lumbar spine and to lesser extent at proximal femur after consumption of isoflavones was observed by a meta-analysis study ${ }^{25}$. Recently, Zhang and colleagues reported decline in the loss of BMD in perimenopausal women after administration of soy isoflavones ${ }^{26}$. On the other hand, several studies reported no beneficial effect of soy isoflavones on $\mathrm{BMD}$ of the spine, the total hip, or the femoral neck neither on bone turnover markers in postmenopausal women ${ }^{27}$

The mechanisms of action of isoflavones on bone are not fully understood. Several mechanisms have been postulated. Genistein 
isoflavone stimulates osteoblasts through binding to ERs which leads to increase bone formation. Moreover, genistein inhibits osteoclasts by promoting the expression of osteoprotegerin, which is an osteoclastogenic inhibitor responsible for neutralizing the effect of RANKL (receptor activator of nuclear factor- $\kappa \mathrm{B}$ ligand) and daidzein induces apoptosis of osteoclasts ${ }^{28}$.

Furthermore, isoflavones increase the synthesis of Insulin-like growth factor 1 (IGF-1) at the bone level and it has been known that IGF-1 increases activity of osteoblasts ${ }^{29}$. There is some incongruity in the literature about the hypocholesterolemic effect of soy isoflavones. In the current study, we reported a beneficial effect of soy isoflavones on lipid profile in the form of a significant decrease in total cholesterol, triglycerides and LDL-c; accompanied by a significant increase in HDL-c. Similar results were reported in a previous meta-analysis study which documented the beneficial effects of soy which were more prominent in hypercholesterolemic, obese and diabetic individuals ${ }^{30}$. In the same context, isoflavones prevented dyslipidemia in rats fed high cholesterol diet ${ }^{31}$. Other studies deduced that soy isoflavones lowered TC and LDL-c but had no effect on TG and HDL-c ${ }^{32}$.

The hypocholesterolemic effect of isoflavones may be exerted through decreasing lipid reabsorption, bile acid synthesis and hepatic lipid synthesis. The underlying mechanism is probably through its action as ligands for peroxisome proliferator activated receptors (PPARs), liver $\mathrm{X}$ receptor, and farnesoid $\mathrm{X}$ receptor ${ }^{33}$. The activation of peroxisome proliferator-activated receptors (PPAR) is also responsible for the effect of soy on glucose metabolism.

A notable decrease is reported currently in fasting insulin after soy ingestion whereas there were no significant changes in fasting glucose and HOMA I-R test. Charles and colleagues observed in their study that ingestion of high dose of soy isoflavones had no effect on serum insulin or blood glucose in healthy menopausal women ${ }^{34}$.

Clinical evidence for hypotensive effect of soy is still controversial. A recent meta-analysis study reviewing clinical studies involving non hypertensives and hypertensive patients revealed that phytoestrogen/ soy derivatives caused insignificant reduction of SBP and DBP ${ }^{35}$ which commensurate with the results of our study where there was no effect of soy ingestion on blood pressure.

On the contrary, a previous meta-analysis of 14 randomized controlled trials revealed that isoflavones ingestion significantly decreases systolic blood pressure but not diastolic blood pressure in normotensive adults. The mechanisms underlying the effect of soy on BP are vasodilatation through interaction with the estrogen-response element of genes related to endothelial nitric oxide (NO) synthase that increases endogenous production of $\mathrm{NO}^{36}$. In addition, animal study reported that soy isoflavones increase renal blood flow and sodium excretion ${ }^{37}$. This mechanism may explain the significant decrease in serum creatinine in our patients after soy ingestion.

There are some concerns about the use of soy in patients with hypothyroidism as it interferes with the absorption of synthetic thyroid hormone. Isoflavones were reported to inhibit the activity of thyroid peroxidase (TPO), an enzyme involved in the synthesis of triiodothyronine (T3) and thyroxine (T4) ${ }^{38}$. A recent meta-analysis study reported soy protein and/or isoflavones supplementation caused a remarkable decrease in TSH with no change in FT3 or FT4 suggesting that despite the adverse effect of soy, it is not clinically significant ${ }^{39}$. Surprisingly, in the current study, we reported a significant decrease in TSH after soy consumption, unfortunately we did not assess FT3 or FT4. None of the participants developed symptoms suggestive of hyperthyroidism. Previous study in pre-ovariectomized monkeys revealed that dietary soy increased triiodothyronine and prevented decline in thyroxine, which suggested that soy protein and isoflavones consumption did not adversely affect or might even preserve thyroid function in postmenopausal women ${ }^{40}$. In addition, the European Food Safety Authority (EFSA) risk assessment on 2015 reported that food supplements containing isolated isoflavones did not cause significant effects on thyroid function in peri- or post-menopausal women ${ }^{41}$. The discrepancy in the results between different studies assessing the effect of soy may be due to differences in the constituents of the soy preparations, doses, durations and the populations chosen for the studies. The study faced some limitations as the decline in the number of the participants due to the prolonged duration of the study as well as the absence of a placebo group where each participant served as her own control.

\section{CONCLUSION}

The study suggests the ingestion of soy bioactive fraction exerted a beneficial effect on bone health in postmenopausal women. It induced a prominent decrease in bone resorption marker along with the increase in bone formation marker. It caused intensification in bone density at proximal femur. Moreover, soy bioactive fraction had a hypocholesterolemic effect with no adverse actions on thyroid and kidney functions. Consequently, soy bioactive fraction can be safely used as a complementary alternative for HRT in postmenopausal women to improve bone health and decrease cardiovascular risk.

\section{REFERENCES}

1. Naftolin F, Friedenthal J, Nachtigall R, Nachtigall L. Cardiovascular health and the menopausal woman: The role of estrogen and when to begin and end hormone treatment [version 1; peer review: 3 approved]. F1000Research. 2019;8. doi:10.12688/f1000research.15548.1

2. Rossouw JE, Anderson GL, Prentice RL, et al. Risks and benefits of estrogen plus progestin in healthy postmenopausal women: Principal results from the women's health initiative randomized controlled trial. Journal of the American Medical Association. 2002;288(3):321-333. doi:10.1001/jama.288.3.321

3. Perna S, Peroni G, Miccono A, et al. Multidimensional effects of soy isoflavone by food or supplements in menopause women: Asystematic review and bibliometric analysis. Natural Product Communications. 2016;11(11):1733-1740. doi:10.1177/1934578x1601101127

4. Carbonel AAF, Simões RS, Girão JHC, et al. Isoflavones in gynecology Revista da Associacao Medica Brasileira. 2018;64(6):560-564. doi:10.1590/1806-9282.64.06.560

5. Murphy PA, Barua K, Hauck CC. Solvent extraction selection in the determination of isoflavones in soy foods. Journal of Chromatography B: Analytical Technologies in the Biomedical and Life Sciences. 2002;777(1-2):129-138. doi:10.1016/S1570-0232(02)00342-2

6. Horwitz W. Official Methods of Analysis of AOAC International. 18th ed. AOAC International; 2005

7. Masuko T, Minami A, Iwasaki N, Majima T, Nishimura SI, Lee YC Carbohydrate analysis by a phenol-sulfuric acid method in microplate format. Analytical Biochemistry. 2005;339(1):69-72. doi:10.1016/j. ab.2004.12.001

8. César IDC, Braga FC, Vianna-Soares CD, Nunan EDA, Pianetti GA, Moreira-Campos LM. Quantitation of genistein and genistin in soy dry extracts by UV-visible spectrophotometric method. Quimica Nova. 2008;31(8):1933-1936. doi:10.1590/S0100-40422008000800003

9. Kamo S, Suzuki S, Sato T. The content of soyasaponin and soyasapogenol in soy foods and their estimated intake in the Japanese. Food Science and Nutrition. 2014;2(3):289-297. doi:10.1002/fsn3.107

10. Watson D. A simple method for the determination of serum cholesterol. Clinica Chimica Acta. 1960;5(5):637-643. doi:10.1016/00098981(60)90004-8

11. Burstein M, Scholnick HR, Morfin R. Rapid method for the isolation of lipoproteins from human serum by precipitation with polyanions. Journal of Lipid Research. 1970;11(6):583-595. Accessed September 9, 2020. https://europepmc.org/article/med/4100998 
12. Assmann G. Determination of LDL Cholesterol and LDL Apolipoprotein B Following Precipitation of VLDL in Blood Serum with Phosphotungstic Acid/MgC12. Clinical Chemistry and Laboratory Medicine. 1984;22(1):35-40. doi:10.1515/cclm.1984.22.1.35

13. Ammar NM, El-Hawary SS, Mohamed DA, et al. Estrogenic Activity Including Bone Enhancement and Effect on Lipid Profile of Luteolin-7-O-glucoside Isolated from Trifolium alexandrinum L. in Ovariectomized Rats. Phytotherapy Research. 2016;30(5):768-773. doi:10.1002/ptr.5564

14. REITMAN S, FRANKEL S. A colorimetric method for the determination of serum glutamic oxalacetic and glutamic pyruvic transaminases. American journal of clinical pathology. 1957;28(1):56-63. doi:10.1093/ ajcp/28.1.56

15. M. Rashed M, Shallan M, A. Mohamed D, Fouda K, M. Hanna L. Biological Evaluation of Anti-androgenic Effect of Some Plant Foods. Journal of Food and Nutrition Research. 2014;2(9):645-651. doi:10.12691/jfnr-2-9-19

16. Turkington RW, Estkowski A, Link M. Secretion of Insulin or Connecting Peptide: A Predictor of Insulin Dependence of Obese 'Diabetics.' Archives of Internal Medicine. 1982;142(6):1102-1105. doi:10.1001/archinte.1982.00340190058011

17. Trinder P. Determination of Glucose in Blood Using Glucose Oxidase with an Alternative Oxygen Acceptor. Annals of Clinical Biochemistry: An international journal of biochemistry and laboratory medicine. 1969;6(1):24-27. doi:10.1177/000456326900600108

18. Matthews DR, Hosker JP, Rudenski AS, Naylor BA, Treacher DF, Turner RC. Homeostasis model assessment: insulin resistance and $\beta$-cell function from fasting plasma glucose and insulin concentrations in man. Diabetologia. 1985;28(7):412-419. doi:10.1007/BF00280883

19. Thiede MA, Smock SL, Petersen DN, Grasser WA, Thompson DD, Nishimoto SK. Presence of messenger ribonucleic acid encoding osteocalcin, a marker of bone turnover, in bone marrow megakaryocytes and peripheral blood platelets. Endocrinology. 1994;135(3):929-937. doi:10.1210/endo.135.3.8070388

20. Coleman RE. The clinical use of bone resorption markers in patients with malignant bone disease. Cancer. 2002;94(10):2521-2533. doi:10.1002/cncr.10522

21. Soos M, Siddle K. Characterization of monoclonal antibodies directed against human thyroid stimulating hormone. Journal of Immunological Methods. 1982;51(1):57-68. doi:10.1016/0022-1759(82)90382-9

22. Current understanding of osteoporosis according to the position of the World Health Organization (WHO) and International Osteoporosis Foundation - PubMed. Ortop Traumatol Rehabil 2007;9(4):337356. Accessed September 9, 2020. https://pubmed.ncbi.nlm.nih. gov/17882114/

23. Pabich M, Materska M. Biological effect of soy isoflavones in the prevention of civilization diseases. Nutrients. 2019;11(7). doi:10.3390/ nu11071660

24. Lee H, Choue R, Lim H. Effect of soy isoflavones supplement on climacteric symptoms, bone biomarkers, and quality of life in Korean postmenopausal women: A randomized clinical trial. Nutrition Research and Practice. 2017;11(3):223-231. doi:10.4162/ nrp.2017.11.3.223

25. Lambert MNT, Hu LM, Jeppesen PB. A systematic review and meta-analysis of the effects of isoflavone formulations against estrogen-deficient bone resorption in peri- and postmenopausal women. American Journal of Clinical Nutrition. 2017;106(3):801-811. doi:10.3945/ajcn.116.151464
26. Zhang $X$, Liu Y, Xu Q, et al. The effect of soy isoflavone combined with calcium on bone mineral density in perimenopausal Chinese women: a 6-month randomised double-blind placebo-controlled study. International Journal of Food Sciences and Nutrition. 2020;71(4):473481. doi:10.1080/09637486.2019.1673703

27. Alekel DL, van Loan MD, Koehler KJ, et al. The Soy Isoflavones for Reducing Bone Loss (SIRBL) study: A 3-y randomized controlled trial in postmenopausal women. American Journal of Clinical Nutrition. 2010;91(1):218-230. doi:10.3945/ajcn.2009.28306

28. Marini H, Minutoli L, Polito F, et al. OPG and sRANKL Serum Concentrations in Osteopenic, Postmenopausal Women After 2-Year Genistein Administration. Journal of Bone and Mineral Research. 2008;23(5):715-720. doi:10.1359/jbmr.080201

29. Chadha $R$, Bhalla $Y$, Jain A, Chadha K, Karan M. Dietary soy isoflavone: A mechanistic insight. Natural Product Communications. 2017;12(4):627-634. doi:10.1177/1934578×1701200439

30. Tokede OA, Onabanjo TA, Yansane A, Gaziano JM, Djoussé L. Soya products and serum lipids: A meta-Analysis of randomised controlled trials. British Journal of Nutrition. 2015;114(6):831-843. doi:10.1017/ S0007114515002603

31. Kobayashi M, Egusa S, Fukuda M. Isoflavone and protein constituents of lactic acid-fermented soy milk combine to prevent dyslipidemia in rats fed a high cholesterol diet. Nutrients. 2014;6(12):5704-5723. doi:10.3390/nu6125704

32. Bakhtiari A, Hajian-Tilaki K, Omidvar S, Nasiri-Amiri F. Clinical and metabolic response to soy administration in older women with metabolic syndrome: A randomized controlled trial. Diabetology and Metabolic Syndrome. 2019;11(1):47. doi:10.1186/s13098-019-0441-y

33. Ricketts ML, Moore DD, Banz WJ, Mezei O, Shay NF. Molecular mechanisms of action of the soy isoflavones includes activation of promiscuous nuclear receptors. A review. Journal of Nutritional Biochemistry. 2005;16(6):321-330. doi:10.1016/j.jnutbio.2004.11.008

34. Charles C, Yuskavage J, Carlson O, et al. Effects of high-dose isoflavones on metabolic and inflammatory markers in healthy postmenopausal women. Menopause. 2009;16(2):395-400. doi:10.1097/gme.0b013e3181857979

35. MA GG, MA RA, A MC, L PL, MA GG. Usefullness of Phytoestrogens in Treatment of Arterial Hypertension. Systematic Review and MetaAnalysis: Un Update. Vol 2. Peertechz; 2016. doi:10.17352/XXXXXXXX.000006

36. Jackson RL, Greiwe JS, Schwen RJ. Emerging evidence of the health benefits of S-equol, an estrogen receptor $\beta$ agonist. Nutrition Reviews. 2011;69(8):432-448. doi:10.1111/j.1753-4887.2011.00400.x

37. Patten GS, Abeywardena MY, Bennett LE. Inhibition of Angiotensin Converting Enzyme, Angiotensin II Receptor Blocking, and Blood Pressure Lowering Bioactivity across Plant Families. Critical Reviews in Food Science and Nutrition. 2016;56(2):181-214. doi:10.1080/1040 8398.2011.651176

38. Chang HC, Doerge DR. Dietary genistein inactivates rat thyroid peroxidase in vivo without an apparent hypothyroid effect. Toxicology and Applied Pharmacology. 2000;168(3):244-252. doi:10.1006/ taap.2000.9019

39. Otun J, Sahebkar A, Östlundh L, Atkin SL, Sathyapalan T. Systematic Review and Meta-analysis on the Effect of Soy on Thyroid Function. Scientific Reports. 2019;9(1):1-9. doi:10.1038/s41598-019-40647-x

40. Silverstein MG, Kaplan JR, Appt SE, Register TC, Shively CA. Effect of soy isoflavones on thyroid hormones in intact and ovariectomized cynomolgus monkeys (Macaca fascicularis). Menopause. 2014;21(10):1136-1142. doi:10.1097/gme.0000000000000223

41. EFSA ANS Panel. Risk assessment for peri- and post-menopausal women taking food supplements containing isolated isoflavones. EFSA Journal. 2015;13(10):4246. doi:10.2903/j.efsa.2015.4246 


\section{GRAPHICAL ABSTRACT}

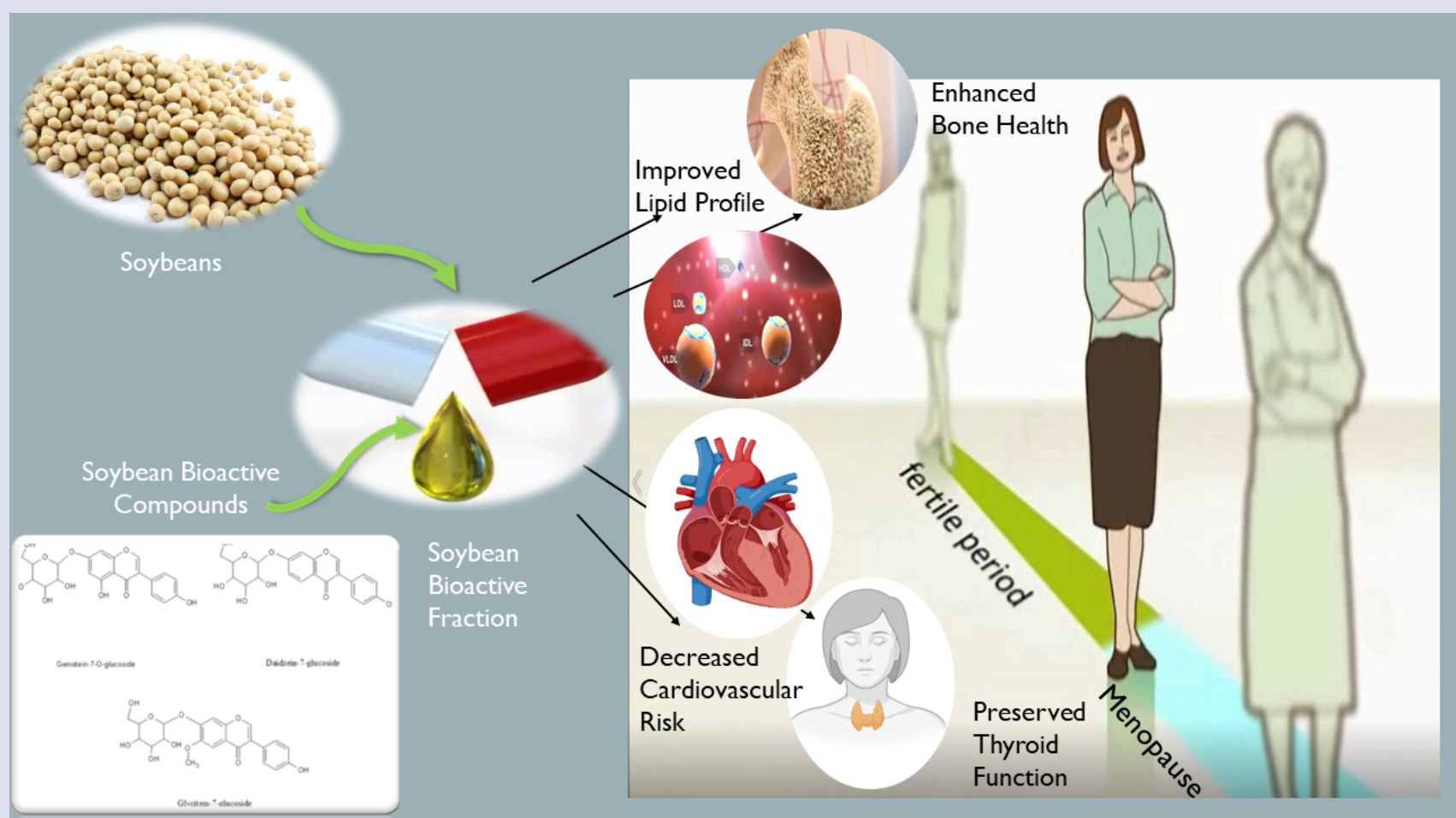

\section{ABOUT AUTHORS}

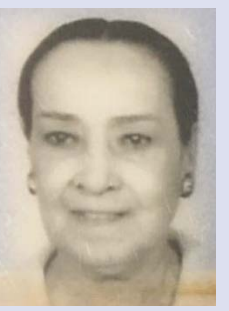

\section{Mouchira Abd EISalam, MD Internal Medicine}

Prof. Emeritus, Department Research \& Applications of CAM, NRC, (2005 till present)

Prof. Emeritus, Human Genetics Department, NRC, (1977 to 2005)

Residence:

Mohandessin City, Cairo, Egypt

Alma Mater:

Pensionnat du Bon Pasteur, Le Caire

Personal goals:

Promote positive \& productive examples in scientific research

practices as well as in everyday life.

Professional goals:

Implement Herbal Medicine in NRC \& EGYPT on scientific \& ethical grounds.

Relevant achievements:

1) Two published papers on plant-based treatments of asthmatic bronchitis \& Osteoporosis.

2) A progressing, promising study on a de novo hypotensive plant mixture.

Hobbies: Poetry

Writing quartets and short poems as portraits for birthdays highlighting some pleasant characteristics of a certain individual or on funny age-related realities.

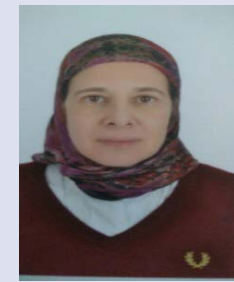

\section{Hala Raslan}

Hala Mohamed Raslan. Professor of Internal medicine and Rheumatology. Internal Medicine department, National Research Centre.

MD internal medicine Kasr Al Aini hospital.

Email: halamzr@yahoo.com 


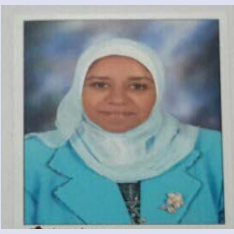

\section{Prof. Dr. Doha Abdou Mohamed}

I'm professor of nutritional biochemistry since 31/7/2011 till now.

I'm Head of Nutrition and Food Sciences Dept., in National

Research Centre, Cairo, Egypt, since 7/8/2018. I published

more than 90 paper, 59 in Scopus journals and supervised more than 20 Ph.D. and MSc Thesis. My $\mathrm{H}$ index is 10 and citation according to Scopus is 378 . I'm reviewer in many international periodical journals.

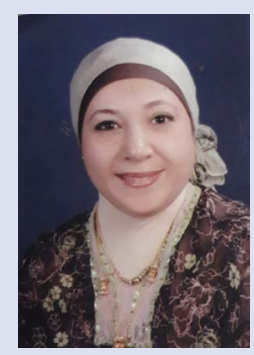

\section{Aliaa Abd El Rahman El Gendy}

Date of birth: $30 / 01 / 1974$

Place of birth: Cairo - Egypt

Address: El haram-Giza

Mobile: 01005200277

Graduated from

faculty of medicine - El Kasr El Eini - Cairo University

MBBcH: 1997 very good

MSc: Rheumatology and rehabilitation - Cairo University - 2003

PHD on Application of laser in internal medicine - Cairo University- 2013

Positions:

House officer: 1998 - 1999 Kasr El Eini Hospitals

Resident in internal medicine - Mubarak Police Hospital: 1999 - 2006

Assistant lecturer in complementary Medicine Department in National Research Center since 2006 lecturer in complementary department in National Research Center since 3 /11/2013.

Assistance professor since 30/11/2019.

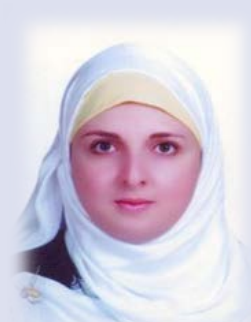

\section{Rehab Ali Hussein}

- Bachelor Degree in Pharmaceutical Sciences from the faculty of Pharmacy, Cairo University in 2002.

- Master in Pharmacognosy, Faculty of Pharmacy,

Cairo University in 2009

- Ph.D. in Pharmacognosy, Faculty of Pharmacy, Cairo University in 2016.

- Currently working in Pharmacognosy Department, Pharmaceutical Science

Division in the National Research Centre in Egypt.

- 14 international publications, H-index: 6, Google scholar index: 8.

- Participation in a number of national and international research projects.

- Member in special service unit in the National research Centre concerned with

the phytochemical investigations of medicinal plants and algae.

- Member of several Committees serving public health and women rights.

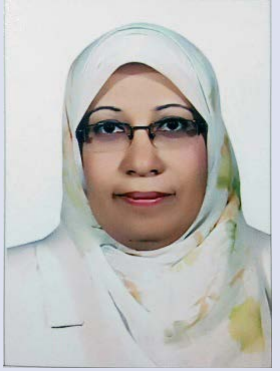

\section{Dr. Omneya Moguib Saleh}

Assistant professor of Endocrinology and Metabolism Internal medicine department, National Research Centre.

MD in Endocrinology and Metabolism from Ain Shams University, Cairo, Egypt, 2008.

Consultant of Diabetes Mellitus and endocrine diseases.

Interested in researches concerning diabetes mellitus and its

complications such as diabetic nephropathy, diabetic neuropathy,

metabolic and bone diseases. 


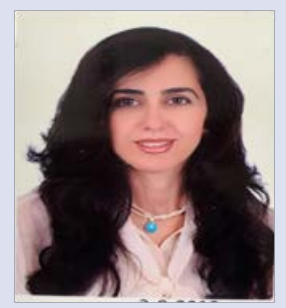

\section{Maha Abdel Hadi Ali Gamal El Din}

Assistant Professor of Rheumatology and Rehabilitation, Internal Medicine Department, National Research Centre, Egypt.

MD degree in Physical Medicine, Rheumatology and Rehabilitation (May 2009).

Clinical Experience in the field of Rheumatology, Rehabilitation and Clinical Immunology since 1999 till now.

Training at Neurophysiology Unit, Cairo University (2012-2014).

Supervisor of the Rheumatology clinic and Electromyography \& Nerve conduction study unit at the Centre of Scientific Excellence of the National Research Centre since 2013 till now.

Attendance and participation of conferences and workshops of Rheumatology and Electromyography from 2008 till now. Participation in local and internal research projects as well as international publications in the field of Rheumatology and Electromyography. Supervision of MD and Master thesis of Rheumatology at NRC. Professional Memberships at Egyptian Medical Syndicate, Egyptian Society of Clinical Neurophysiology, Egyptian Society of Rheumatology, Egyptian Society of Ultrasound in Obstetrics and Gynecology, Arab Society of Medical Research and Organization of Women Sciences in Developing World (OWSD).

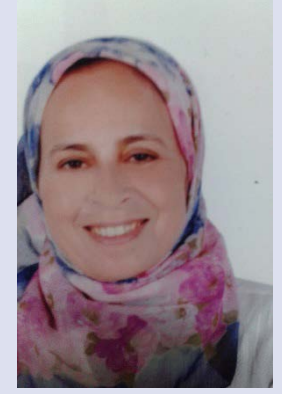

\section{Prof. Dr. Rokia Abd El-Shafy Soliman El-Banna}

Biological Anthropology Department. Medical Sciences Division (NRC). Experience and Publications in Biological Anthropology, Osteoporosis, Pale anthropology, ancient Egyptian skeletal remains and obesity. Head of Bone mineral density unit, Center of Excellence from 2005. Participated in more than 120 conferences local and international as Speaker, Attended and Chairperson or Organizer. Supervised many Master and Ph.D. scientific theses more than (40) in addition to reviewing and discussing other theses as external examiner. More than 30 of Training Courses as Organizer, lecturer and Attendee. Member of many scientific societies and Scientific Projects.

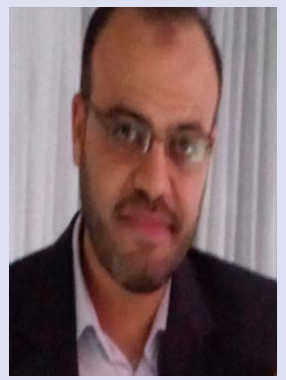

\section{Karem El-Sayed Aly Fouda}

Assistant Professor of Nutritional biochemistry

National Research Centre

Nutrition and food sciences department

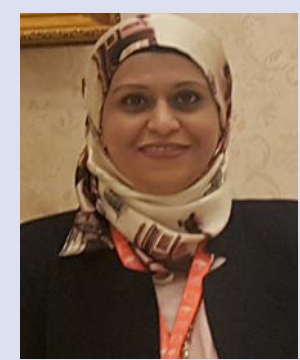

\section{Dr. Safenaz Youssif El Sherity}

Radiology consultant; had MB.B.CH, Faculty of Medicine, Ain shams University, December 2003, M.Sc. Degree of Radiodiagnosis, Faculty of Medicine, Ain Shams University, November 2007 and MD Degree of Radiodiagnosis, Faculty of Medicine, Ain shams University, May 2014. I am an Assistant Professor at Biological Anthropology Department, National Research Center (NRC), February 2020, also I am the head of radiological department at Medical Research Centre of Excellence (MRCE). I participated in conerences as speaker and published researches at international journals \& participated in many projects. Also, I am a member in Egyptian societies. 


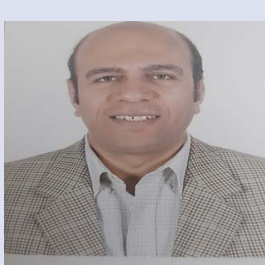

\section{Emad Nasr Zikri MD MSc, PhD}

Associate Professor of Complementary and Internal Medicine, National Research Center, Cairo, Egypt. Tel: 01207579824

Email: emadzikri@hotmail.com

I am a medical doctor with 28 years of clinical practice. I began my career as a general practitioner in Cairo University Hospital (Egypt). I awarded my PhD degree in Internal Medicine and Laser, Laser Institute, Cairo, Egypt. I am working in National Research Center at the clinics of Internal Medicine and laser acupuncture. I participated in many research projects and published various papers in international journals.

April 2019 till now

Associate Professor of Complementary and Internal Medicine, Complementary and Alternative Medicine department, National Research Center, Cairo, Egypt.

April 2017 till April 2019

Instructor of laser application in Medicine in Wellness Center, Columbus, Ohio, United States.

Researcher of Internal and Complementary Medicine (November 2011 to May 2017)

Assistant Researcher of Internal Medicine and Laser (August 1998 to October 2011)

Internal medicine specialist (February 1993 to July 1998)

House officer (January 1992 to February 1993)

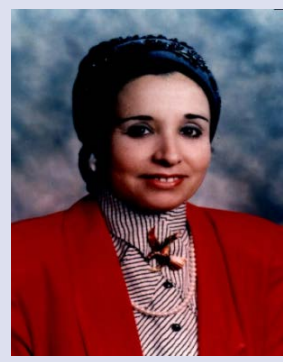

\section{Nagwa Mohamed Issa Ammar}

Professor of applied pharmacognosy, graduated from Faculty of Pharmacy, Cairo University in 1973, with B. Pharm. \& Pharm. Sci. Awarded the M. Pharm. Sc. and Ph.D. from Cairo University in pharmacognosy in 1978 and 1982 respectively.

She participated in 20 scientific projects in the field of applied pharmacognosy, supervised 30 graduates for M. Sc. and Ph. D. degrees. Published 100 papers in National and International Journals. She is a contributor of a new drug from natural origin for the treatment of contact dermatitis. She was awarded a patent from the Egyptian Academy of Sciences and Technology.

She awarded the NRC Prize in Pharmaceutical Sciences (1989), the NRC Prize of the Scientific Creation (2005), the appreciation State Prize of the NRC in Medical Sciences (2013), The Silver Medal on the occasion of the NRC Silver Jubilee (1982), A Certificate from the NRC for Scientific evaluation (2011 and 2012), The Silver Medal from the Egyptian Pharmacists Syndicate (2005), and the honor as a woman of the year (2006) from (American Biographical Institute, Inc., USA).

Cite this article: Salam MA, Raslan HM, Mohamed DA, Elgendy A, Hussein RA, et al. Effect of Soybean on Bone Health and Some Metabolic Parameters in Postmenopausal Egyptian Women. Pharmacog J. 2021;13(3): 688-97. 